\title{
The cognitive advantage for one's own name is not simply familiarity: An eye-tracking study
}

\author{
Hongsheng Yang • Fang Wang • Nianjun Gu • Xiao Gao • \\ Guang Zhao
}

Published online: 4 April 2013

(C) Psychonomic Society, Inc. 2013

\begin{abstract}
Eye-tracking technique and visual search task were employed to examine the cognitive advantage for one's own name and the possible effect of familiarity on this advantage. The results showed that fewer saccades and an earlier start time of first fixations on the target were associated with trials in which participants were asked to search for their own name, as compared to search for personally familiar or famous names. In addition, the results also demonstrated faster response times and higher accuracy in the former kind of trials. Taken together, these findings provide important evidence that one's own name has the potential to capture attention and that familiarity cannot account for this advantage.
\end{abstract}

Keywords Self-related information - Cocktail-party effect . Cognitive advantage $\cdot$ Attention capture

Due to its personal salience and strong emotional arousal, self-related information has demonstrated a consistent cognitive advantage in a large number of studies using various approaches (Brédart, Delchambre, \& Laureys, 2006; Keenan, Freund, Hamilton, Ganis, \& Pascual-Leone, 2000; Moray, 1959; Symons \& Johnson, 1997; Tong \& Nakayama,

H. Yang $(\bowtie) \cdot X$. Gao

Key Laboratory of Cognition and Personality (SWU),

Ministry of Education,

Chongqing 400715, China

e-mail: yanghs.swu@gmail.com

H. Yang

Research Center for Psychology and Social Development (SWU), Chongqing, China

H. Yang $\cdot$ F. Wang $\cdot$ N. Gu $\cdot$ X. Gao $\cdot$ G. Zhao

School of Psychology, Southwest University, Chongqing, China
1999). Among these findings is the well-known "cocktail party effect," which shows that one's own name can be detected easily, even under unattended conditions. Since Moray's famous study, the cognitive advantage for perceiving one's own name has been established in both auditory and visual modalities (Harris, Pashler, \& Coburn, 2004; Wolford \& Morrison, 1980; Wood \& Cowan, 1995). It has also been shown that one's own name can be resistant to the attentional blink and repetition blindness (Arnell, Shapiro, \& Sorensen, 1999; Shapiro, Caldwell, \& Sorensen, 1997).

Despite such findings, however, evidence has been inconsistent about whether one's own name has an advantage in capturing attention. While some studies have confirmed that one's own name can pop out of an array of up to 12 items, reduce the attentional blink in rapid serial visual presentation, and disrupt performance of a primary task (Mack \& Rock, 1998; Shapiro et al., 1997; ShelleyTremblay \& Mack, 1999; Wolford \& Morrison, 1980), others have found that it did not cause more interference than did other names when used as a distractor (Bundesen, Kyllingsbæk, Houmann, \& Jensen, 1997; Harris et al., 2004; Kawahara \& Yamada, 2004). There is also evidence that one's own name gains cognitive priority only when it is presented within the focus of attention or when participants are set to identify it (Gronau, Cohen, \& Ben-Shakhar, 2003; Kawahara \& Yamada, 2004).

Another issue that remains unresolved is whether familiarity might influence the cognitive advantage for one's own name. Given the high familiarity inherent in self-related information, it seems quite reasonable to attribute this advantage to familiarity in some way. Surprisingly, however, little research has been done to address this issue. The few studies that have employed familiar names as control stimuli have focused on the neural basis of self-name recognition and yielded inconsistent results (Qin et al., 2012; Sugiura et al., 2008; 
Tacikowski, Brechmann, Marchewka, Jednoróg, Dobrowolny, \& Nowicka, 2011; Tacikowski, Jednoróg, Marchewka, \& Nowicka, 2011). Moreover, these studies relied on a simple familiar/unfamiliar discrimination task, which has made it difficult to address the issue of attentional capture.

In the present study, the eye-tracking technique was used to investigate these two issues. Measurements of eye movements can provide an objective psychophysiological marker of visual attention in real time (Just \& Carpenter, 1976; Noton \& Stark, 1971). Saccade paths, locations of fixations, gaze durations, and times of occurrence are more revealing about the spatiotemporal location of attention than are indirect measures, such as response times (RTs) or percentages correct. Specifically, two indexes of eye movement were adopted in the present research: mean numbers of saccades and the start time of the first fixation. The mean number of saccades refers to the number of eye movements necessary for participants to judge correctly whether the target is present or absent. The start time of the first fixation is the time point at which participants first fixate their eyes on the target. It was hypothesized that, if one's own name can capture attention and if familiarity is not the crucial factor in this advantage, trials featuring one's own name would elicit a lower number of saccades and an earlier start time of first fixations, as compared with trials featuring other names, including familiar names.

In order to explore the role of familiarity in the cognitive advantage for one's own name, two kinds of manipulations were employed. In the first, we controlled for the familiarity of names prior to task exposure and selected control names that were either (1) personally familiar to the individual participant or (2) the names of famous people. In the second, we accounted for changes in familiarity occurring within the task by dividing trials of each name category into two halves and examining differences in performance that could be attributed to task-related name repetitions (Tacikowski, Jednoróg et al., 2011).

\section{Method}

Participants

A group of 24 Chinese college students (14 female, 10 male) participated in this experiment. Their mean age was 21.8 years $(S D=1.53$, range $=19$ to 25$)$. All participants were righthanded, had normal vision, gave informed consent, and were paid for their participation.

\section{Materials}

All of the stimuli were names written in Chinese characters and displayed visually on a computer screen. The stimuli included participant's own name, his or her mother's name, one famous name, and 100 other common Chinese names. The common names were used as distractor items in the visual search task; among them were no personally familiar names. By preexperimental screening of the volunteers and names, all of these stimuli were matched for character length and stroke number within each individual participant.

Eye movements were recorded with an SR Research EyeLink CL system with a temporal resolution of $500 \mathrm{~Hz}$.

\section{Procedure}

The experiment consisted of three blocks, each including 96 trials and requiring participants to search for one specific target: their own name, their mother's name, or the famous name. Within each block, the target name was present in half of the trials. The order of the different blocks was counterbalanced across participants. At the end of each block, participants were given feedback about their hit rate in the preceding block.

Each trial began with a fixation cross. After $500 \mathrm{~ms}$, six names were evenly presented around a central point and formed a virtual circle of $14^{\circ}$, based on a viewing distance of $65 \mathrm{~cm}$. Participants were asked to judge as quickly and accurately as possible whether the target name was present. The stimuli remained present for up to $2 \mathrm{~s}$ until participants gave a response, and was followed by a blank screen of 1,000 ms. The frequencies with which target names appeared were equal for the six positions. In each trial, distractor names were chosen randomly from the total list of 100 common names.

\section{Results}

Behavioral data

For each participant, RTs exceeding three standard deviations (SDs) above or below the mean were removed within each task. A repeated measures analysis of variance (ANOVA) showed significantly different search speeds for the three target names, $F(2,46)=65.85, p<.001, \eta_{\mathrm{p}}^{2}=.74$. The mean RT for participant's own name $(M=820 \mathrm{~ms}, S D=118)$ was shorter than for either the mother's name $(M=1,080 \mathrm{~ms}, S D=125)$ or

Table 1 Response times (in milliseconds) for participants' own name, personally familiar name, and famous names during the first and last half of the trials

\begin{tabular}{llll}
\hline & Participant's Own Name & Mother's Name & Famous Name \\
\hline First half & $828(129)$ & $1,057(125)$ & $1,112(110)$ \\
Last half & $812(119)$ & $1,105(148)$ & $1,111(138)$ \\
\hline
\end{tabular}


Table 2 Eye movement data for participants' own name, personally familiar name, and famous names

\begin{tabular}{|c|c|c|c|}
\hline & $\begin{array}{l}\text { Participant's Own } \\
\text { Name }\end{array}$ & $\begin{array}{l}\text { Mother's } \\
\text { Name }\end{array}$ & $\begin{array}{l}\text { Famous } \\
\text { Name }\end{array}$ \\
\hline Number of saccades & $3.2(0.68)$ & $4.5(0.65)$ & $4.7(0.55)$ \\
\hline $\begin{array}{l}\text { Time of first fixation } \\
\text { on target (ms) }\end{array}$ & $597(96)$ & $774(134)$ & $784(94)$ \\
\hline
\end{tabular}

the famous name $(M=1,112 \mathrm{~ms}, S D=113), p \mathrm{~s}<.001$. A comparison between the RTs for the latter two names did not show any difference, $p>.05$.

Hit rates for the three target names were compared and also demonstrated a significant difference, $F(2,46)=16.26$, $p<.001, \eta_{\mathrm{p}}^{2}=.41$, with participant's own name $(M=97.5 \%)$ being recognized more accurately than the other two names, $p$ s $<.001$, while no difference emerged between the mother's name $(M=91.2 \%)$ and the famous name $(M=91.6 \%)$, $p>.05$. The identity of the names had no effect on false alarm rates (own name, $0.95 \%$; parent's name, $0.61 \%$; famous name, $0.61 \%), F(2,46)=0.36, p>.05$.

To examine the possible effect of repetition on the cognitive advantage for one's own name, the data for each kind of name category were further divided into two subsequent phases, each including half of the trials with target names. The mean RTs for each half are shown in Table 1. No effect of repetition was found in a two-way repeated measures ANOVA, as neither the Name Category $\times$ Phase interaction nor the main effect of phase was significant, $F(2,46)=2.56$ and $F(1,23)=0.902$, respectively, $p \mathrm{~s}>.05$. In comparison, the main effect of name category was significant, $F(2,46)=65.90$, $p<.001, \eta_{\mathrm{p}}^{2}=.74$.

Eye movement data

Consistent with the RT results, the cognitive advantage for one's own name was also demonstrated in the eye movement data, as is shown in Table 2. The mean numbers of saccades necessary for participants to detect specific target names were significantly different, $F(2,46)=50.91, p<.001, \eta_{\mathrm{p}}^{2}=.69$ : They made fewer saccades when searching for their own names than for their mothers' names or for famous names, $p \mathrm{~s}<.001$; we found no difference between the latter two target names, $p>.05$. Similar results were also obtained for the start times of first fixations, $F(2,46)=27.27, p<.001, \eta_{\mathrm{p}}^{2}=.54$. The start time when participants first fixated their eyes on the target name was earlier for their own names than for either their mothers' names or famous names, $p \mathrm{~s}<.001$; no difference was found between the latter two name categories on this index, $p>.05$.

The eye movement data were divided in the same manner as the RT data, to examine the effects of repetition. The mean numbers of saccades and the start times of first fixations were recomputed for each half of the trials within each name category (see Table 3 for the results). A two-way repeated measures ANOVA showed no evidence of an effect of repetition on the mean numbers of saccades. Neither the main effect of phase nor the Name Category $\times$ Phase interaction was significant $-F(1,23)=0.05$ and $F(2,46)=1.51$, respectively, $p \mathrm{~s}>.05$ - while the main effect of name category was significant, $F(2,46)=50.82, p<.001, \eta_{\mathrm{p}}^{2}=.69$. We observed fewer saccades on trials with one's own name than in those with the mother's or the famous name, $p \mathrm{~s}<.001$; no difference was significant between trials with the latter two name categories, $p>.05$. Statistical analysis of the start times of first fixations demonstrated a similar pattern. The main effect of name category was significant, $F(2,46)=$ 27.31, $p<.001, \eta_{\mathrm{p}}^{2}=.54$ : Participants' own names were fixated earlier than either their mothers' names or the famous names, $p \mathrm{~s}<.001$. The difference did not change across the two halves of the trials, as the Name Category $\times$ Phase interaction was not significant, $F(2,46)=0.76, p>.05$. No difference between the other two name categories was found, $p>.05$, and the main effect of phase was not significant either, $F(1,23)=0.27, p>.05$.

\section{Discussion}

Consistent with previous studies using visual search tasks (Harris et al., 2004; Mack \& Rock, 1998), the present study demonstrated a cognitive advantage for self-related information. Response time data showed that participants were significantly faster to detect their own name than to detect personally familiar or famous names. Moreover, the eye movement data provided further evidence for this advantage, as participants demonstrated earlier first fixations on their names and fewer saccades than in the other name

Table 3 Eye movement data for participants' own name, personally familiar name, and famous names during the first and last halves of the trials

\begin{tabular}{|c|c|c|c|c|c|c|}
\hline & \multicolumn{2}{|c|}{ Participant's Own Name } & \multicolumn{2}{|c|}{ Mother's Name } & \multicolumn{2}{|c|}{ Famous Name } \\
\hline & First Half & Last Half & First Half & Last Half & First Half & Last Half \\
\hline Number of saccades & $3.3(0.67)$ & $3.2(0.72)$ & $4.4(0.70)$ & $4.5(0.74)$ & $4.6(0.48)$ & $4.7(0.71)$ \\
\hline Time of first fixation on the target (ms) & $597(94)$ & $597(111)$ & $761(133)$ & $788(172)$ & $785(100)$ & $784(116)$ \\
\hline
\end{tabular}


conditions. Since eye movements constitute an implicit measure of visual performance and do not necessarily involve conscious processes (Hayhoe, 2004; Hayhoe, Bensinger, \& Ballard, 1998), the earlier start times of first fixations and the fewer saccades suggest that one's own name can automatically capture attention.

More importantly, the results showed that mere familiarity cannot account for the cognitive advantage of one's own name, as the two kinds of manipulations of familiarity employed in the current research did not confirm this. When searching for their own names, as compared to both personally familiar (mothers' names) and famous names, participants demonstrated faster and more efficient behavioral responses as well as eye movements. Furthermore, this attentional advantage held even after 24 repetitions in the first half of trials and 20 practice trials. In fact, other, indirect evidence has also supported these findings. For example, when participants were asked to respond positively to an assumed "own" name and to reject as false all other names, including their real name, the N380 component of the evoked brain potential to the real name was more similar to that elicited by other names than was the N380 of the assumed name (Fischler, Jin, Boaz, Perry, \& Childers, 1987). While the assumed name was not more familiar to participants than were the other names, the larger difference between this and the other names than between the real name and the others suggested that self-specificity is mostly due to self-relevance rather than to familiarity. Also, one's own screen name has been demonstrated to elicit visual search speeds similar to that for one's real name, while both were detected faster than famous names (Yang, Wang, Gu, \& Huang, 2012). As the familiarity of a screen name was obviously less than the familiarity of both one's own real name and famous names, these results also provided evidence for the argument that familiarity cannot explain the cognitive advantage for one's own name.

In spite of the positive evidence above, the present findings of dissociation between self-specificity and familiarity are inconsistent with results from Tacikowski and colleagues (Tacikowski, Brechmann, et al., 2011; Tacikowski, Jednoróg, et al., 2011), which showed that personally familiar names and participant's own name elicited similar patterns of neural activation, as compared to unfamiliar names, when participants made familiar-versus-unfamiliar discriminations between stimuli presented on the auditory channel. The inconsistency between this work and our results may be due to differences in the task requirements. In Tacikowski et al.'s studies, participants' own names, personally familiar names, and famous names were all categorized similarly and assigned the same response (i.e., "familiar"). In the present research, however, participants searched for each name in different blocks. It has been shown that one common category label, per se, is sufficient to eliminate own-group bias in face memory and to alter attitudes toward members previously belonging to another category (Hehman, Mania, \& Gaertner, 2010; Nier et al., 2001). Thus, in the studies of Tacikowski and colleagues (Tacikowski, Brechmann, et al., 2011; Tacikowski, Jednoróg, et al., 2011), grouping one's own name and other familiar names into one common category might have reduced the difference between them. In addition, the visual search task and the eye-tracking technique used in the present study are arguably more suitable to measuring attentional capture than is a simple auditory discrimination task.

Taken together, the present findings provide strong evidence that one's own name captures attention in comparison to other names. Importantly, familiarity cannot account for this advantage. Given that the participants were Chinese students and that they typically maintained a highly intimate connection with their parents in the collectivist Chinese culture, the cognitive advantage for their own name as compared to their mother's name demonstrated that selfspecificity and familiarity are dissociable. However, it should be noted that the task used in the present research explicitly required participants to search for specific names on the basis of their identity, while some studies using a participant's own name as a distractor have not found evidence to support the more powerful interfering effect of this name (Bundesen et al., 1997). As a result, the faster processing speed and more efficient eye movement pattern for one's own name demonstrated in the present research may exist only under conditions in which the identity of names is task-relevant.

Author Note This research was supported by funds from the Chongqing Key Research Base for the Humanities and Social Sciences (09SKB26), the Fundamental Research Funds for the Central Universities (SWU1309002), a Team Research Project of Faculty of Psychology (TR201203-6), and the Doctoral Research Fund of Southwest University (SWU109040). We thank Stephen L. Crites Jr., Tingyong Feng, Matt Nassar, and Qi Chen for their helpful comments on earlier drafts of this article.

\section{References}

Arnell, K. M., Shapiro, K. L., \& Sorensen, R. E. (1999). Reduced repetition blindness for one's own name. Visual Cognition, 6 , 609-635.

Brédart, S., Delchambre, M., \& Laureys, S. (2006). One's own face is hard to ignore. Quarterly Journal of Experimental Psychology, 59, 46-52.

Bundesen, C., Kyllingsbæk, S., Houmann, K. J., \& Jensen, R. M. (1997). Is visual attention automatically attracted by one's own name? Perception \& Psychophysics, 59, 714-720. doi:10.3758/ BF03206017

Fischler, I., Jin, Y. S., Boaz, T. L., Perry, N. W., \& Childers, D. G. (1987). Brain potentials related to seeing one's own name. Brain and Language, 30, 245-262.

Gronau, N., Cohen, A., \& Ben-Shakhar, G. (2003). Dissociations of personally significant and task-relevant distractors inside and outside the focus of attention: A combined behavioral and 
psychophysiological study. Journal of Experimental Psychology. General, 132, 512-529. doi:10.1037/0096-3445.132.4.512

Harris, C., Pashler, H., \& Coburn, P. (2004). Moray revisited: Highpriority affective stimuli and visual search. Quarterly Journal of Experimental Psychology, 57A, 1-31.

Hayhoe, M. M. (2004). Advances in relating eye movements and cognition. Infancy, 6, 267-274.

Hayhoe, M. M., Bensinger, D. G., \& Ballard, D. H. (1998). Task constraints in visual working memory. Vision Research, 38, $125-137$.

Hehman, E., Mania, E. W., \& Gaertner, S. L. (2010). Where the division lies: Common ingroup identity moderates the cross-race facial-recognition effect. Journal of Experimental Social Psychology, 46, 445-448.

Just, M. A., \& Carpenter, P. A. (1976). The role of eye-fixation research in cognitive psychology. Behavior Research Methods, 8, 139-143. doi:10.3758/BF03201761

Kawahara, J., \& Yamada, Y. (2004). Does one's name attract visual attention? Visual Cognition, 11, 997-1017.

Keenan, J. P., Freund, S., Hamilton, R. H., Ganis, G., \& PascualLeone, A. (2000). Hand response differences in a self-face identification task. Neuropsychologia, 38, 1047-1053.

Mack, A., \& Rock, I. (1998). Inattentional blindness. Cambridge: MIT Press.

Moray, N. (1959). Attention in dichotic listening: Affective cues and the influence of instructions. Quarterly Journal of Experimental Psychology, 11, 56-60.

Nier, J. A., Gaertner, S. L., Dovidio, J. F., Banker, B. S., Ward, C. M., \& Rust, M. C. (2001). Changing interracial evaluations and behavior: The effects of a common group identity. Group Processes and Intergroup Relations, 4, 299-316.

Noton, D., \& Stark, L. (1971). Eye movements and visual perception. Scientific American, 224, 34-43.

Qin, P., Liu, Y., Shi, J., Wang, Y., Duncan, N., Gong, Q., et al. (2012). Dissociation between anterior and posterior cortical regions during self-specificity and familiarity: A combined fMRI-meta- analytic study. Human Brain Mapping, 33, 154-164. doi:10.1002/hbm.21201

Shapiro, K. L., Caldwell, J., \& Sorensen, R. E. (1997). Personal names and the attentional blink: A visual "cocktail party" effect. Journal of Experimental Psychology. Human Perception and Performance, 23, 504-514. doi:10.1037/0096-1523.23.2.504

Shelley-Tremblay, J., \& Mack, A. (1999). Metacontrast masking and attention. Psychological Science, 10, 508-515.

Sugiura, M., Sassa, Y., Jeong, H., Horie, K., Sato, S., \& Kawashima, R. (2008). Face-specific and domain-general characteristics of cortical responses during self-recognition. NeuroImage, 42, 414-422.

Symons, C. S., \& Johnson, B. T. (1997). The self-reference effect in memory: A meta-analysis. Psychological Bulletin, 121, 371-394. doi:10.1037/0033-2909.121.3.371

Tacikowski, P., Brechmann, A., Marchewka, A., Jednoróg, K., Dobrowolny, M., \& Nowicka, A. (2011). Is it about the self or the significance? An fMRI study of self-name recognition. Social Neuroscience, 6, 98-107. doi:10.1080/17470919.2010.490665

Tacikowski, P., Jednoróg, K., Marchewka, A., \& Nowicka, A. (2011). How multiple repetitions influence the processing of self-, famous and unknown names and faces: An ERP study. International Journal of Psychophysiology, 79, 219-230. doi:10.1016/ j.ijpsycho.2010.10.010

Tong, F., \& Nakayama, K. (1999). Robust representations for faces: Evidence from visual search. Journal of Experimental Psychology. Human Perception and Performance, 25, 1016-1035.

Wolford, G., \& Morrison, F. (1980). Processing of unattended visual information. Memory \& Cognition, 8, 521-527. doi:10.3758/ BF03213771

Wood, N., \& Cowan, N. (1995). The cocktail party phenomenon revisited: How frequent are attention shifts to one's name in an irrelevant auditory channel? Journal of Experimental Psychology: Learning, Memory, and Cognition, 21, 255-260.

Yang, H. S., Wang, F., Gu, N. J., \& Huang, X. T. (2012). Processing priority for self-related information: Evidence from visual search of screen names. Acta Psychologica Sinica, 44(4), 489-497. 